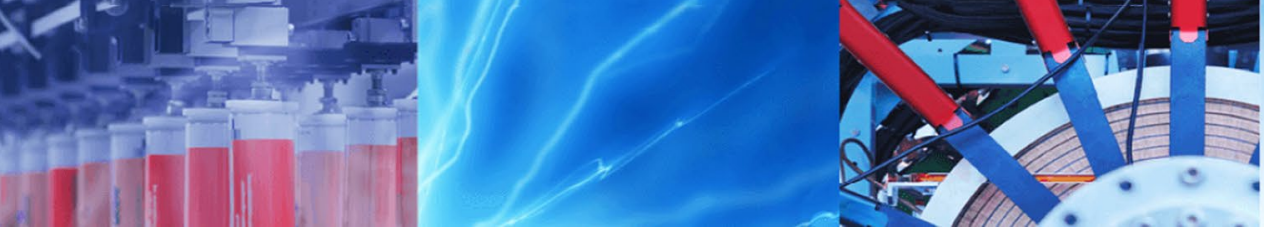

Research Article

\title{
Polymeric nanostructures for photocatalytic dye degradation: polyaniline for photocatalysis
}

\author{
Shreya Saha ${ }^{1} \cdot$ Nahid Chaudhary $^{1} \cdot$ Arun Kumar $^{1} \cdot$ Manika Khanuja $^{1}$ (D)
}

Received: 2 January 2020 / Accepted: 15 May 2020 / Published online: 22 May 2020

(c) Springer Nature Switzerland AG 2020

\begin{abstract}
The motivation for the work presented in this paper comes from the need to explore novel and efficient photocatalysts for the degradation of contaminants from waste water. In this regard and in addition to the existing class of semiconductor photocatalysts, polymeric structures such as polyaniline, have emerged with the potential to degrade common water contaminants through photocatalysis. This paper elucidates the preparation of polyaniline (PANI) nanofibers and its implementation as a photocatalyst for the degradation of organic dyes such as Methylene Blue (MB) and Methyl Orange (MO). PANI was obtained using oxidative polymerisation and was examined for morphological and structural properties using XRD, SEM, TEM and FTIR which confirmed the formation of fibrous PANI sample. The chemical composition and the bonding states were studied using XPS. Subsequently, photo induced degradation of MB was performed in the presence of PANI as photocatalyst which indicated $42 \%$ degradation while $\mathrm{MO}$ was degraded by $97 \%$ in less than $3 \mathrm{~h}$. Kinetic analysis by pseudo first order, second order and intra particle diffusion model, showed well-fit results for first order kinetic model with a rate constant of $0.0505\left(\mathrm{~g} \mathrm{mg}^{-1} \mathrm{~min}^{-1}\right)$. The photocatalytic efficiency of PANI was assigned to the $\pi-\pi^{*}$ transition wherein the excited state electrons were transferred from the $\pi$ to the $\pi^{*}$ orbital. Therefore, polyaniline was observed to be a promising photocatalyst for the degradation of environmental pollutants.
\end{abstract}

Keywords Conducting polymers · Dyes/pigments · Catalysis · XPS

\section{Introduction}

Since the last few decades, there has been a continuous search for suitable and efficient catalysts for degradation of dye contaminants in waste water, splitting of water to produce hydrogen, etc. In this regard, semiconductor photocatalysis has been superior in attracting attention of researchers, which is mainly attributable to its low cost, clean and environment friendly technology [1]. In wake of the need for semiconductor photocatalysts, several nanostructured materials have been developed and studied, such as $\mathrm{TiO}_{2}[2,3], \mathrm{ZnO}[4,5]$ and $\mathrm{CdS}[6,7]$, etc. Among these, $\mathrm{TiO}_{2}$ has been broadly investigated due to its stability and versatility [8]. However, the use of this germane material is limited by its inability to absorb photons beyond the UV range due to its large band gap [9]. This drawback maybe resolved by doping $\mathrm{TiO}_{2}$ with transition metals like nickel and zirconium which allows greater absorption of visible light [10]. Core shell nanoparticles of $\mathrm{TiO}_{2}$ with neodymium, have also shown effectiveness in degrading organic dyes such as Methyl Orange and Rhodamine B [11] while neodymium oxide has shown photocatalytic activity towards degradation of industrial azo dye Eriochrome black T [12]. In addition to $\mathrm{TiO}_{2}$, nanoparticles of $\mathrm{ZnO}$, synthesized using plant extracts, have been successfully employed for the photocatalytic degradation of organic dyes [13, 14]. Based on similar lines, green synthesis of silver nanoparticles

$\triangle$ Manika Khanuja, manikakhanuja@gmail.com | ${ }^{1}$ Center for Nanoscience and Nanotechnology, Jamia Millia Islamia, New Delhi 110125, India. 
and magnetic nanocomposites $(\mathrm{Fe}, \mathrm{Si}, \mathrm{Cu}-\mathrm{Ag})$ using fruit extracts, for the purpose of organic dyes' degradation, have also been reported $[15,16]$. Apart from nanoparticles, ZnO nanorods doped with different amounts of copper, synthesized by thermal decomposition process, for degradation of organic dyes has shown promising results $[17,18]$. Hydrothermally synthesized $\mathrm{BiVO}_{4}$ nanoparticles, tested for environmental remediation activities, have also been successful in degrading water pollutants [19]. Nanocomposites of boron oxides and bismuth oxides and oxyhalides have also been obtained using sol gel method, as catalysts for photochemical destruction of water pollutants [20-24]. Although semiconductor nanoparticles lead as successful photocatalysts in the degradation of industrial water effluents, they still offer a major disadvantage which results from the rapid recombination of electron hole pairs, thereby reducing their photocatalytic efficiency [25]. Therefore, there's a need to look for alternate solutions to address the shortcomings posed by conventional photocatalysts and this may be addressed by introducing novel photocatalysts such as polymers.

Another class of novel materials that holds the potential to serve as a promising photocatalyst is, conducting polymers. These polymers have found usage in a number of fields such as electronic devices like light emitting diodes, transistors and solar cells $[26,27]$ and may also be employed for degradation of water contaminants. Polymeric photocatalysts offer several advantages such as chemical inertness, thermal stability and high surface areas $[28,29]$. By selecting different combinations and ratios of building blocks and the degree of polymerization, different optoelectronic and photophysical properties can be administered in the polymer, such as high absorption area, tunable band gaps, and stable excited states, etc. [30]. Also, charge migration in 2D polymers can be improved by pi stacking, which provides a percolation channel within the layers [31]. Among the reported polymeric photocatalysts, poly(diphenylbutadiyne) (PDPB) nanofibers have shown high photocatalytic efficiency under visible light for the degradation of pollutants like phenol and methylene blue [25] while poly(3-hexylthiophene) (P3HT) has indicated higher degradation profiles compared to commercial titania [9]. In view of above, conducting polymers may be considered a fitting solution to the problems posed by existing technologies for waste water treatment.

Herein, we report the photocatalytic activity of conducting polymer polyaniline (PANI) which is known for its easy synthesis and environmental stability [32]. Applications of PANI have been widely explored, including rechargeable batteries [33], organic field transistors [34, 35] and polymer light diodes [36]. However, the photocatalytic efficiency of PANI has not been examined yet which could open new possibilities for this material to be utilized for photocatalysis and therefore an attempt has been made to discover the usefulness of this promising polymer for the same.

\section{Experimental section}

\subsection{Materials}

Aniline $\left(\mathrm{C}_{6} \mathrm{H}_{5} \mathrm{NH}_{2}\right.$ with max impurity limit of $0.02 \%$, Central Drug House Pvt. Ltd), Hydrochloric Acid ( $\mathrm{HCl} \cdot \mathrm{H}_{2} \mathrm{O}$ with max impurity limit of $0.0316 \%$, Thermo Fisher Scientific India Pvt. Ltd) and Ammonium per sulphate $\left(\left(\mathrm{NH}_{4}\right)_{2} \mathrm{~S}_{2} \mathrm{O}_{8}\right.$ with max. impurity limit of $0.005 \%$, Sisco Research Laboratories Pvt. Ltd.

\subsection{Synthesis procedure}

The first step in the synthesis of polyaniline involved the refrigeration of a mixture of aniline $(1 \mathrm{ml}), \mathrm{HCl}(3 \mathrm{ml})$ and DI water $(16 \mathrm{ml})$, for $3 \mathrm{~h}$. This step was followed by the addition of APS ( $13 \mathrm{ml}, 0.1 \mathrm{M}$ in $50 \mathrm{ml})$ to the refrigerated suspension, and stirring for $3 \mathrm{~h}$. The next step involved filtration of the solution and subsequent washing of the precipitate with DI water and ethanol. The precipitate was dried in vacuum at $80^{\circ} \mathrm{C}$ for $2 \mathrm{~h}$ and PANI was finally obtained. The schematic process is shown in Fig. 1.

\subsection{Characterization}

The morphology and structural properties of PANI were observed using a Quanta 3D FEG, (FEl's) Scanning Electron Microscope (SEM) and TECNAI F30 S-Twin Transmission electron microscopy (TEM) operating at an acceleration voltage of $300 \mathrm{kV}$. Rigaku Smart Lab X -ray diffractometer with $\mathrm{Cu} \mathrm{K} \mathrm{K}_{\mathrm{a}}$ radiation at $1.540 \AA$ in the $2 \theta$ range of $20^{\circ}-90^{\circ}$ was used to study crystal structure and phase determination. High Resolution Fourier Transform Infrared Spectroscopy (HR-FTIR) was carried out using Bruker Optik, Vertex $70 \mathrm{~V}$ spectrometer. The sample was scanned in the range of $400-4000 \mathrm{~cm}^{-1}$ with a step size of $4 \mathrm{~cm}^{-1}$. Chemical composition of the synthesized sample was examined using X-Ray photoelectron spectroscopy. The high resolution XPS measurements were carried out using monochromatic Al Ka radiation source (1486.7 eV) at $300 \mathrm{~W}$. An Omicron Hemispherical analyzer with 7 channels detector system was used for data acquisition. The calibration of the spectrometer and binding energy (BE) was carried out using standard gold $(\mathrm{Au})$ sample procedure. 
Fig. 1 Synthesis procedure of PANI

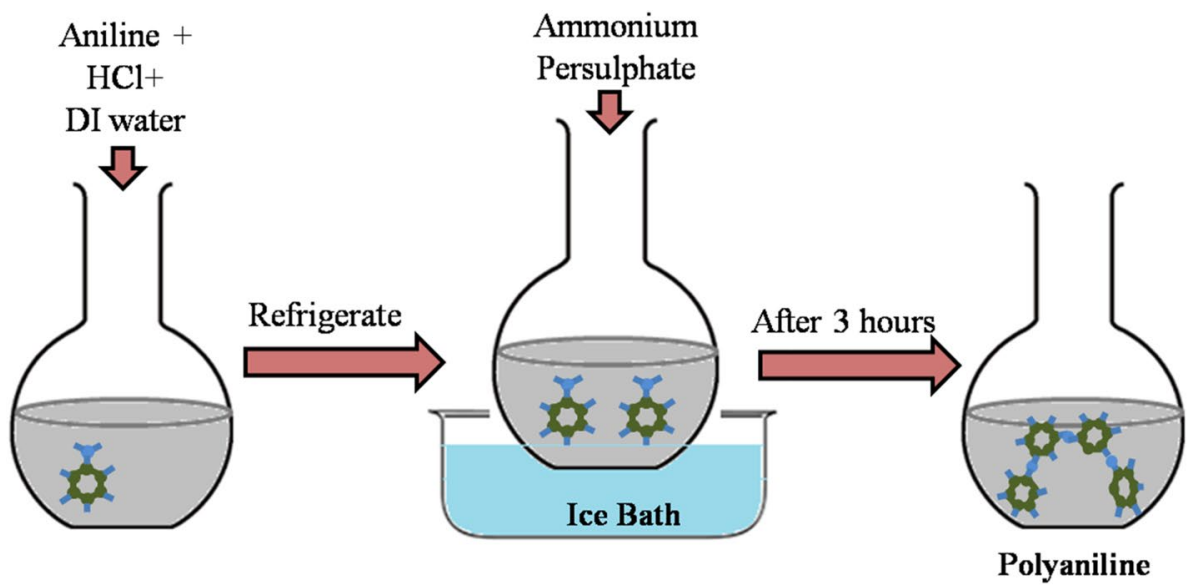

\subsection{Photocatalytic experiments}

The photocatalytic activity of PANI was investigated using Newport Research Arch Lamp Housing, model no. 66902 (50-500 W) which was connected to an external power supply. The concentration of PANI for photocatalysis of $M B$, was kept at $5 \mathrm{mg} / 100 \mathrm{ml}$ while the quantity of $\mathrm{MB}$ taken was $0.33 \mathrm{mg}$. For photocatalysis of $\mathrm{MO}$, the concentration of $\mathrm{MO}$ was kept at $1 \mathrm{mg} / 100 \mathrm{ml}$ while variable quantities, 10,30 and $50 \mathrm{mg}$ of PANI were taken for the experiments. The dark reaction was performed for 30 min followed by irradiation with UV light $\left(100 \mathrm{~W} \mathrm{~cm}^{-2}\right)$. After fixed time intervals of 15 and $30 \mathrm{~min}$ for $\mathrm{MB}$ and $\mathrm{MO}$ respectively, $1 \mathrm{ml}$ aliquots were sampled out of the main solution to study the change in the concentration of $\mathrm{MB}$ and $\mathrm{MO}$ by observing their absorption spectra at 664 and $475 \mathrm{~nm}$, respectively, using UV-Vis spectroscopy.

\section{Results and discussion}

\subsection{TEM analysis}

The micromorphology and structure of synthesized PANI samples were analyzed by TEM as shown in Fig. $2 a$, $b$. The figure shows thin layers of PANI that stack together to form agglomerates. The PANI layers appear to be dark and blurry which may be due to poor crystallinity.
Fig. 2 a, $\mathbf{b}$ TEM images of PANI; $\mathbf{c}, \mathbf{d}$ SEM images of PANI sample
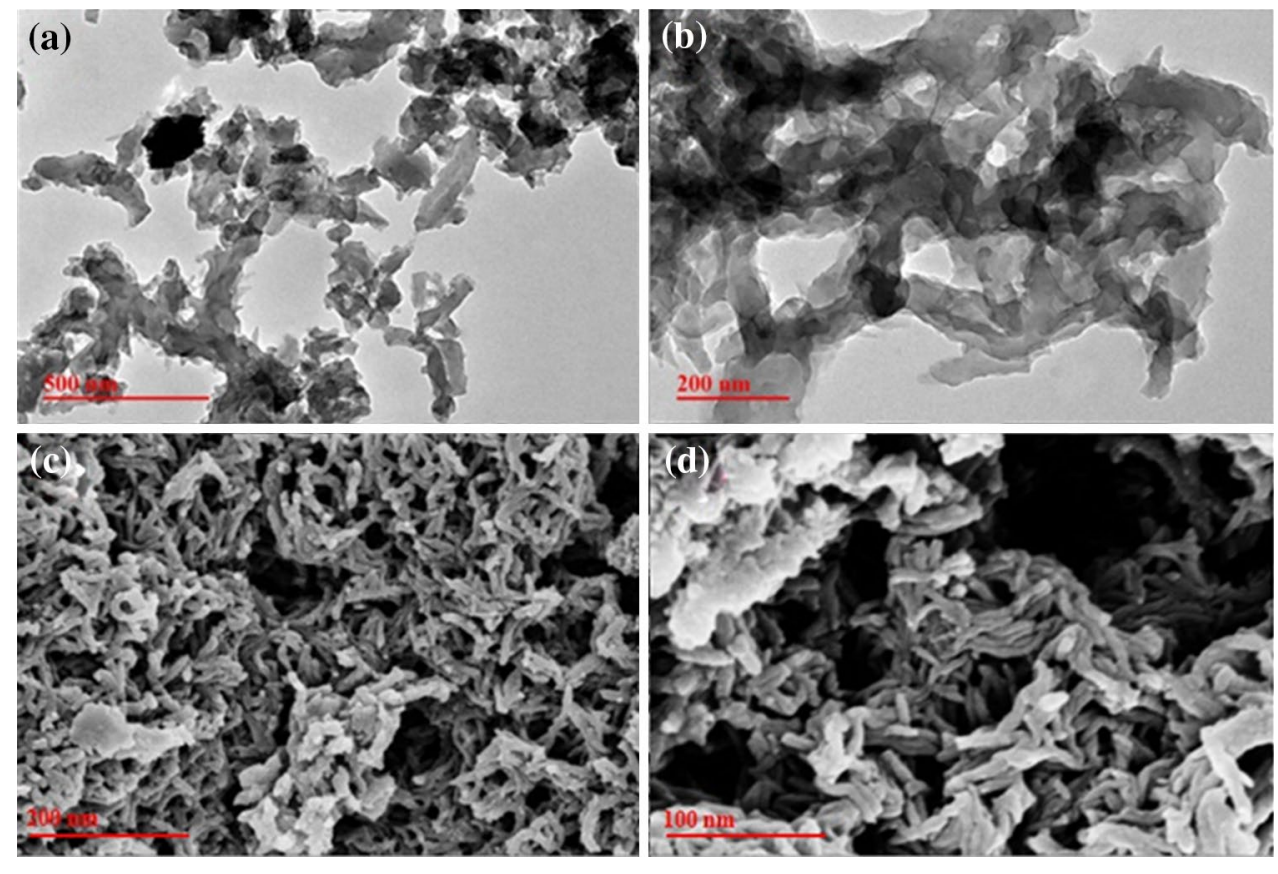

SN Applied Sciences A SPRINGER NATURE journa 


\subsection{SEM analysis}

Figure 2c, d shows typical SEM images of PANI at different magnifications. The images clearly indicate the nanofibrous structure of PANI, aligned randomly, confirming the formation of PANI [37]. PANI nanofibers are usually formed during homogenous nucleation where rapid consumption of reactants prevents secondary growth [38].

\subsection{FTIR analysis}

FTIR studies, as shown in Fig. 3 revealed characteristic peaks of PANI at $608,801,1131,1273$ and $1414-1550 \mathrm{~cm}^{-1}$. The peak at $608 \mathrm{~cm}^{-1}$ indicates $\mathrm{C}-\mathrm{C}$ bonding mode of aromatic ring, while the peak at $801 \mathrm{~cm}^{-1}$ is assigned to the $\mathrm{C}-\mathrm{H}$ out of plane deformation in the benzene ring. The small peak at $1131 \mathrm{~cm}^{-1}$ is characteristic of PANI and represents the aromatic in-plane bending vibration of $\mathrm{C}-\mathrm{H}$. The peak at $1273 \mathrm{~cm}^{-1}$ is attributed to $\mathrm{C}-\mathrm{N}$ stretching vibration of aromatic amine. The peaks from 1414 to $1550 \mathrm{~cm}^{-1}$ are a result of $\mathrm{C}=\mathrm{C}$ stretching mode of vibration for the benzenoid and quinoid rings and $\mathrm{C}-\mathrm{H}$ stretching in the polymer produces characteristic peak at $2520 \mathrm{~cm}^{-1}$ [39-41].

\subsection{UV-Vis analysis}

The UV-Vis absorbance spectrum of polyaniline is shown in Fig. 4. Two characteristic peaks were observed in the range of 296-326 nm and at $666 \mathrm{~nm}$. The peak positioned at $296 \mathrm{~nm}$ is assigned to $\pi-\pi^{*}$ transition occurring in the polymer backbone of the benzoid ring and corresponds to a bandgap of $4.18 \mathrm{eV}$. The second adsorption peak positioned at $666 \mathrm{~nm}$ appears as a result of formation of

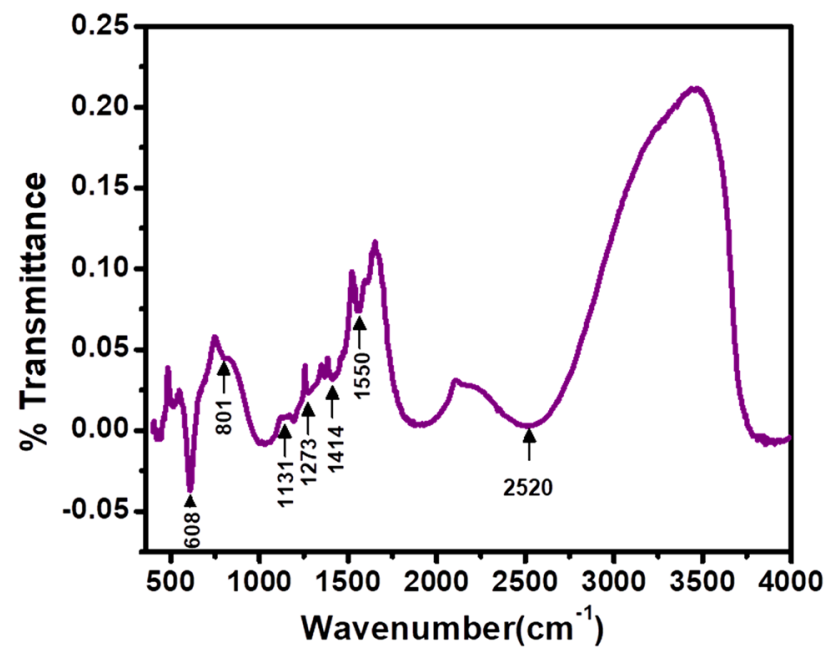

Fig. 3 FTIR analysis of PANI

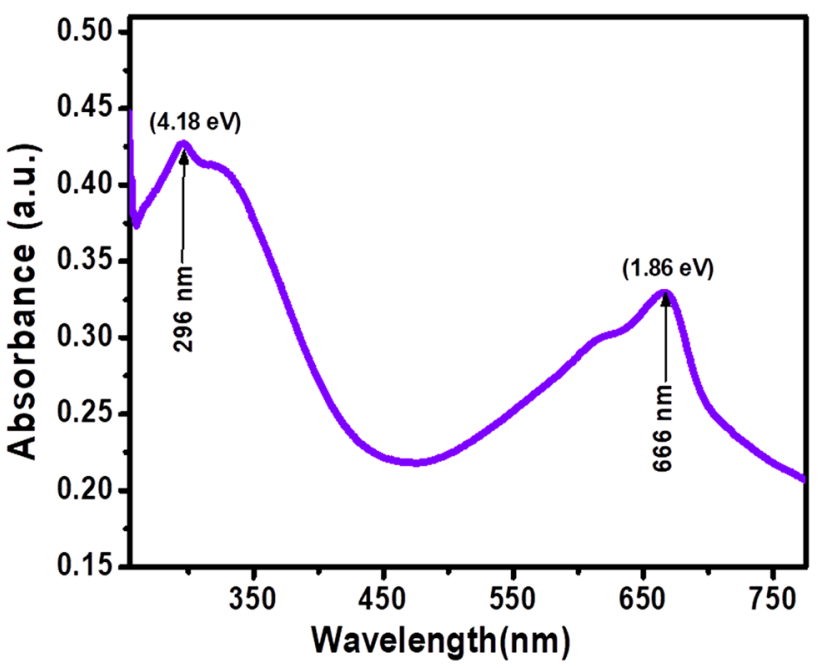

Fig. 4 UV-Vis absorbance spectrum of PANI

exciton in the quinoid ring of PANI corresponding to the bandgap of $1.86 \mathrm{eV}$ [42-44].

\subsection{XPS analysis}

The electronic state of PANI was analyzed using XPS and the survey scans of XPS spectra are as shown in Fig. 5. The deconvolution spectrum of $C 1 \mathrm{~s}$ revealed four peaks at 284.6, 286.01, 287.56 and $289 \mathrm{eV}$. The standard peak at $284.6 \mathrm{eV}$ is attributed to neutral $\mathrm{C}-\mathrm{C} / \mathrm{C}-\mathrm{H}$ bonds which form the backbone of PANI, while the second peak at $286.01 \mathrm{eV}$ represents carbon bonded to oxygen i.e. $\mathrm{C}=\mathrm{O} / \mathrm{C}-\mathrm{O}$ bond [45]. The third peak at $287.56 \mathrm{eV}$ represents $\mathrm{sp}^{2}$ bonded carbon [46] while the peak positioned at $289 \mathrm{eV}$ indicates $\mathrm{O}-\mathrm{C}=\mathrm{O}$ bond [47]. The deconvoluted spectrum for $\mathrm{N} 1 \mathrm{~s}$ shows three peaks positioned at 398.9, 399.6 and $400.9 \mathrm{eV}$. The first peak is assigned to quinone diimine nitrogen while the second peak is attributed to benzenoid diamine nitrogen [45]. The third contribution at $400.9 \mathrm{eV}$ indicates positively charged nitrogen [48]. The resolved spectrum of $\mathrm{O} 1 \mathrm{~s}$ showed three peaks. The first peak at $531.6 \mathrm{eV}$ occurs as a result of formation of carboxylate groups. The second peak centered at $533.4 \mathrm{eV}$ occurs due to the formation of hydroxides while the peak at $535.7 \mathrm{eV}$ is a result of chemisorbed oxygen/water $[48,49]$.

\section{Kinetic analysis}

Aqueous solutions of $\mathrm{MB}$ and $\mathrm{MO}(\mathrm{mg})$ were used to examine the effect of PANI as a photocatalyst on the degradation of dye particles, when irradiated with UV light for a period of over an hour. The decrease in the concentration of $\mathrm{MB}$ and $\mathrm{MO}$ was determined by recording the reduction in the 

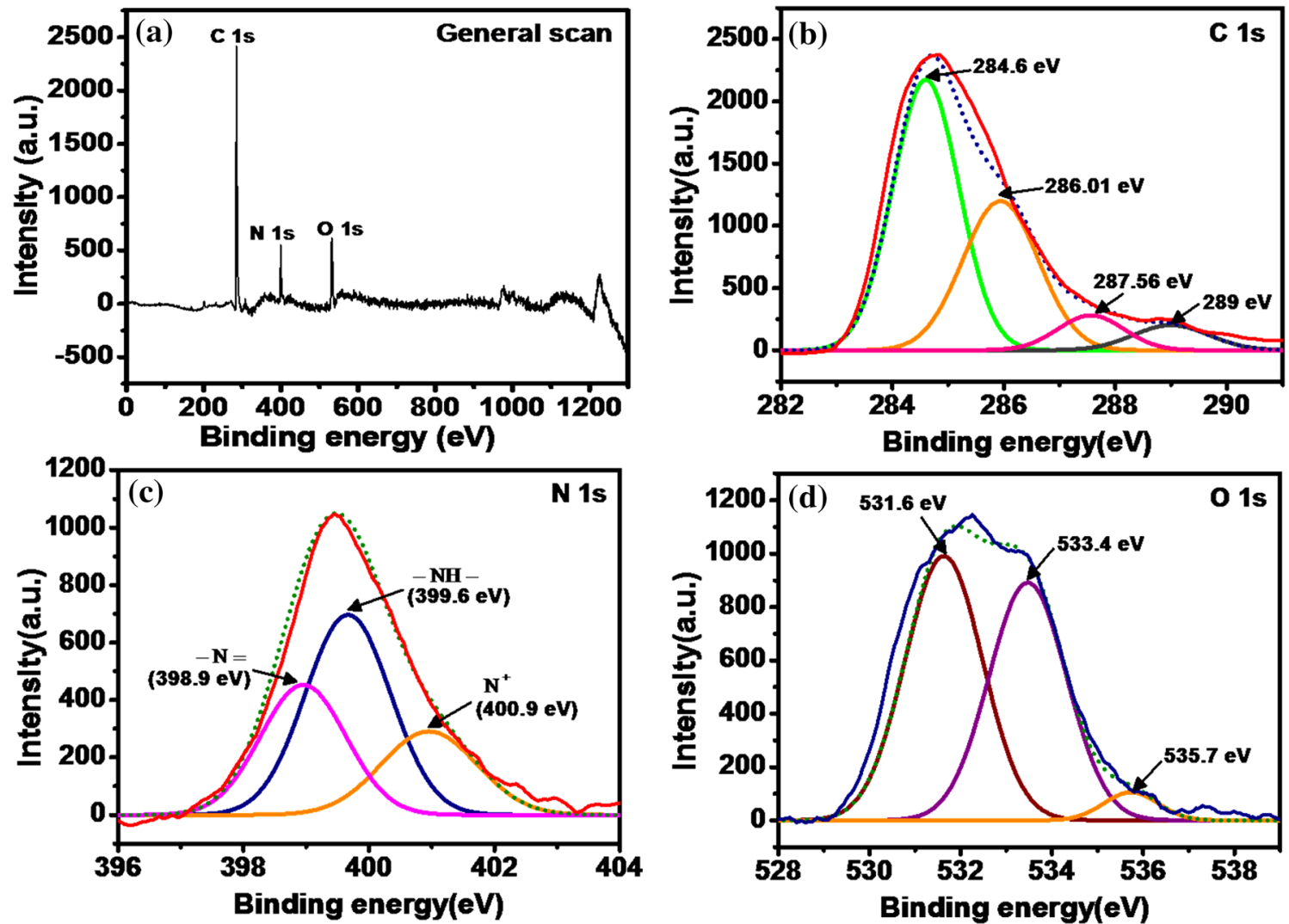

Fig. 5 XPS deconvoluted spectra for a general scan, b C 1s, c N 1s, d O 1s of PANI

absorbance spectra of MB at $664 \mathrm{~nm}$ and $\mathrm{MO}$ at $475 \mathrm{~nm}$, at time intervals of $15 \mathrm{~min}$ and $30 \mathrm{~min}$ respectively. There was almost $42 \%$ degradation in the concentration of $M B$ (Fig. 6), in a span of less than $2 \mathrm{~h}$ which is higher than that of some polymeric nanocomposites [50] and composite semiconductors for the degradation of anionic dyes [51]. PANI also exhibited a remarkable photocatalytic efficiency by showing $97 \%$ degradation in the concentration of $\mathrm{MO}$ (Fig. 7a). The difference in the degradation efficiency for $\mathrm{MB}$ and $\mathrm{MO}$ can be corroborated by the zeta potential of PANI which was found to be $+15.7 \mathrm{eV}$ (Fig. 8). This explains the improved photodegradation efficiency of PANI for anionic dyes which is facilitated by the positive zeta potential value. Hence, PANI shows poor selectivity towards cationic dyes such as MB. Figure 7b shows the degradation profile of $\mathrm{MO}$ as a function of variable PANI concentration. The concentration of $\mathrm{MO}$ was maintained at $1 \mathrm{mg} / 100 \mathrm{ml}$ while 3 different concentrations of PANI were studied i.e. 10,30 and $50 \mathrm{mg}$. Prior to UV irradiation, the solution was kept in the dark for $30 \mathrm{~min}$. As seen from the figure, the degradation of $\mathrm{MO}$ was enhanced with the increase in the concentration of PANI. The values of $\mathrm{C} / \mathrm{Co}$ for 10,30 and 50 mg PANI were: $1,0.79,0.60,0.26,0.16,0.06,0.05 ; 1,0.65$, $0.48,0.37,0.24,0.13,0.03 ; 1,0.17 .0 .05,0.02$, respectively.

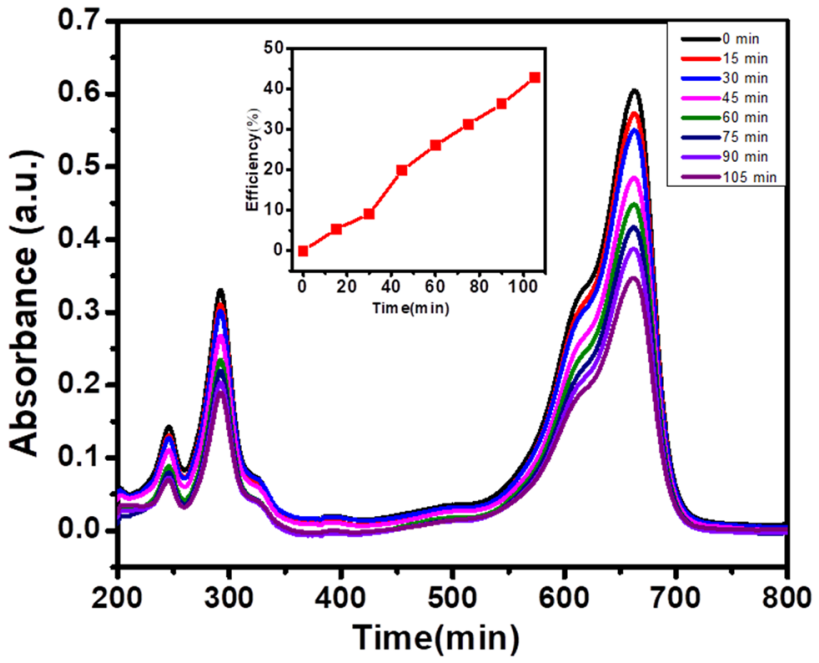

Fig. 6 Degradation of $M B$ in the presence of PANI, inset graph shows the photocatalytic efficiency of PANI photocatalyst for MB degradation

MO showed faster degradation in the presence of $50 \mathrm{mg}$ PANI, comparatively moderate degradation in the presence of $30 \mathrm{mg}$ PANI and much slower degradation when 

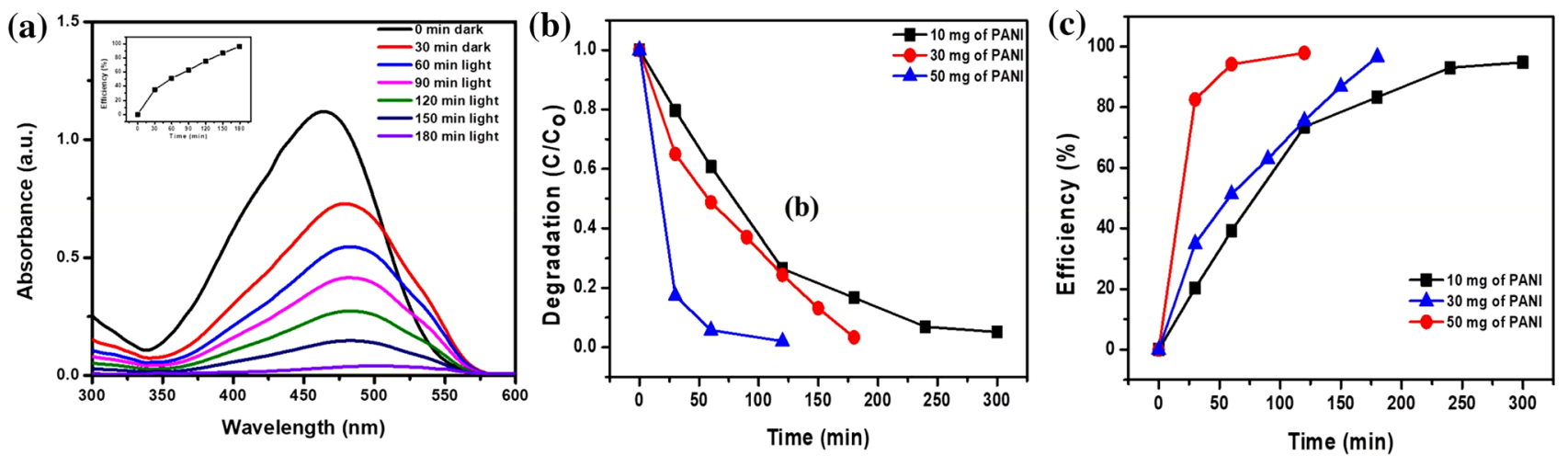

Fig. 7 a Degradation of $\mathrm{MO}$ in the presence of PANI, inset graph shows the photocatalytic efficiency of PANI photocatalyst; Effect of different concentrations, 10,30 and $50 \mathrm{mg}$ of PANI on photocatalysis showing $\mathbf{b}$ degradation profile and $\mathbf{c}$ efficiency of PANI

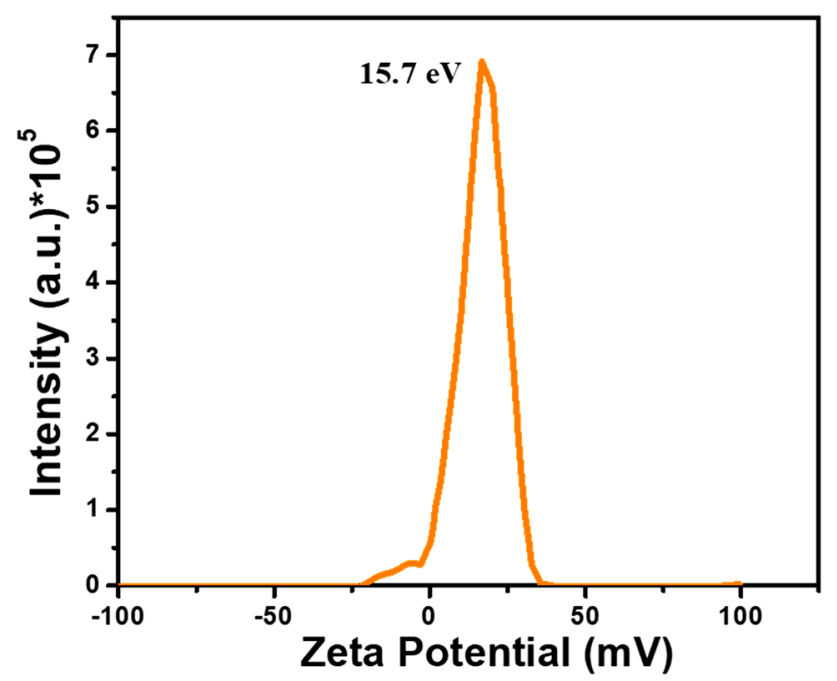

Fig. 8 Zeta potential of PANI

$10 \mathrm{mg}$ of PANI was used. In terms of photocatalytic efficiency, $10 \mathrm{mg}$ PANI showed $94.84 \%$ degradation of $\mathrm{MO}$ in $5 \mathrm{~h}$ while $30 \mathrm{mg}$ PANI could degrade $96.66 \%$ of $\mathrm{MO}$ in $3 \mathrm{~h}$, whereas $50 \mathrm{mg}$ PANI took $2 \mathrm{~h}$ to produce an efficiency of 97.95\% as shown in Fig. 7c.

Based on the performance of PANI in degrading MB, its photocatalytic efficiency $(\eta)$ was calculated using the formula:

$\eta=\frac{C-C_{0}}{C_{0}} \times 100$

where $C_{0}$ is the initial concentration, $C$ is the concentration at time $t$ ( $\mathrm{min}$ ). Figure 6 shows the effect on the absorbance spectra of $\mathrm{MB}$ in the presence of PANI, while the inset graph shows the efficiency of PANI as a photocatalyst.

The degradation profile $\left(C / C_{0}\right.$ vs. time) is shown in Fig. 9a. It can be deduced from the graph that the initial adsorption stage is faster as a result of high concentration, followed by a slower adsorption stage as the concentration decreases. Further investigations for kinetic analysis were carried out using two popular adsorption kinetic representations, pseudo first order and second order adsorption models. For these experiments, a small quantity $(5 \mathrm{mg})$ of MB was used to slower down the adsorption process.

The pseudo first order adsorption model is given by the equation:

$Q_{t}=Q_{e}\left(1-e^{-k_{1} t}\right)$

where

$Q_{e}=\left(C_{0}-C_{e}\right) \times V / W$

$Q_{t}=\left(C_{0}-C_{t}\right) \times V / W$

Here $Q_{t}\left(\mathrm{mg} \mathrm{g}^{-1}\right)$ is the amount of dye adsorbed at time $t$ (min), $Q_{e}\left(\mathrm{mg} \mathrm{g}^{-1}\right)$ is the amount of dye adsorbed at equilibrium time, $\mathrm{k}_{1}\left(\mathrm{~g} \mathrm{mg}^{-1} \mathrm{~min}^{-1}\right)$ is the pseudo first order rate constant, $C_{e}\left(\mathrm{mg} \mathrm{L}^{-1}\right)$ is the equilibrium concentration, $\mathrm{C}_{\mathrm{t}}$ is the concentration at time $\mathrm{t}(\mathrm{min}), \mathrm{V}(\mathrm{L})$ is the volume of the solution and $\mathrm{W}(\mathrm{g})$ is the amount of PANI used for MB dye adsorption $[52,53]$. The pseudo first order equation describes adsorption taking place at certain conditions such as low solute concentration or when equilibrium is reached [54]. This equation illustrates a weak adsorption process i.e. physiosorption which is dependent on van der Waals interaction between the adsorbate (MB) and adsorbent (PANI). There is negligible chemical interaction involved between the adsorbate and adsorbent [52]. The fitting results of pseudo first order model are shown in Fig. $9 \mathrm{~b}$. The slope of the graph gave the value of the first order rate constant $\left(k_{1}\right)$ which was 0.0505 . The value of 

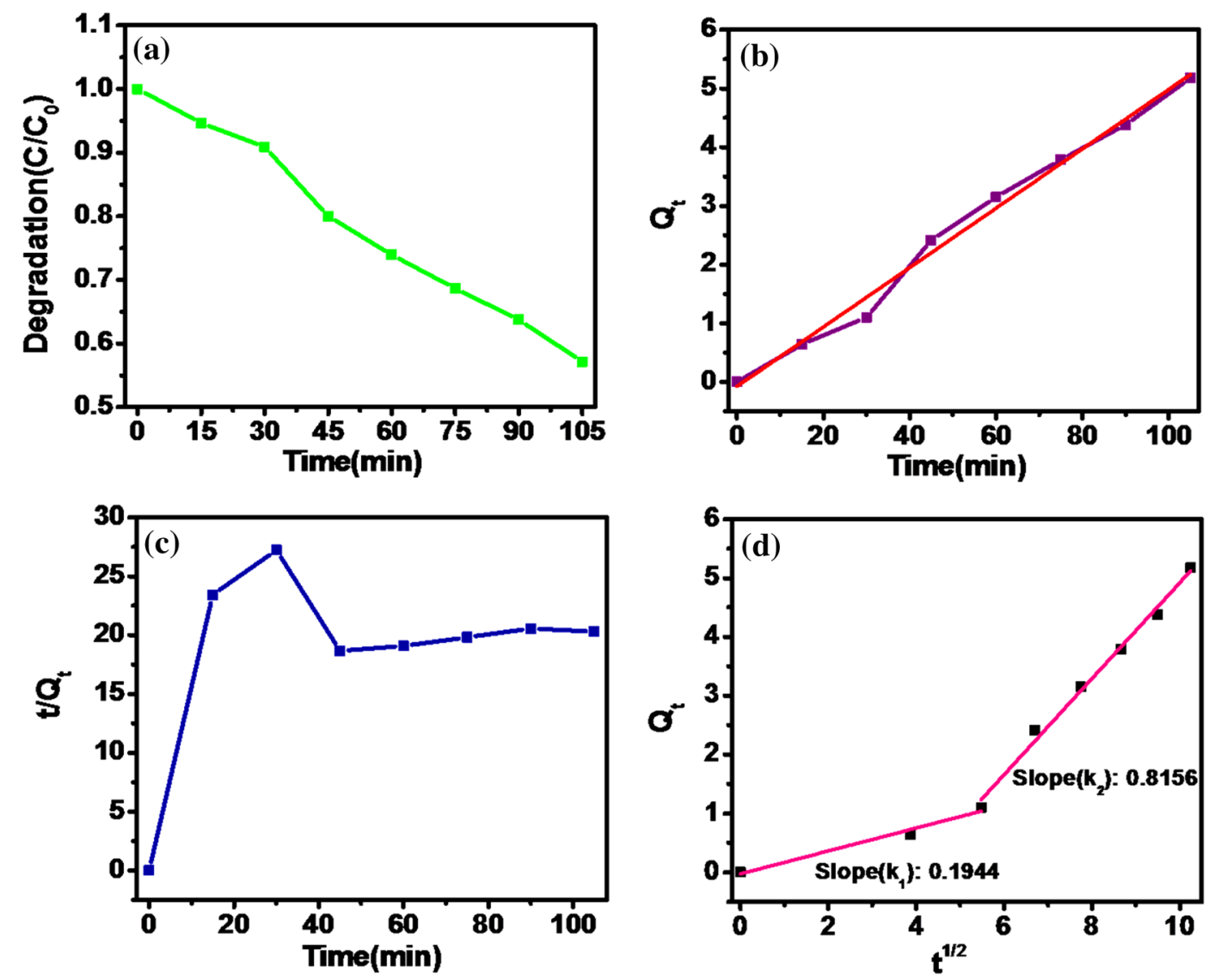

Fig. 9 a Degradation profile of MB in the presence of PANI, $\mathbf{b}$ pseudo first order plot, c pseudo second order plot, $\mathbf{d}$ intra-particle diffusion model with two different rate constants $\mathrm{k}_{1}$ and $\mathrm{k}_{2}$

correlation coefficient $\left(R^{2}\right)$ was 0.9894 and this high value indicated that the reaction followed first order kinetics.

The Pseudo second order adsorption model is given by the equation:

$\frac{t}{Q_{t}}=\frac{1}{k_{2} Q_{e}^{2}}+\frac{t}{Q_{e}}$

where $k_{2}$ is the second order rate constant. The second order equation signifies chemisorption process wherein stronger bonds exist between the adsorbent and adsorbate, unlike physiosorption process.

Figure $9 \mathrm{c}$ shows the fitting results of pseudo second order adsorption model. The second order rate constant was found to be 0.0838 with very low values of $R^{2}(0.0048)$ confirming the inapplicability of second order rate kinetics.

Apart from pseudo first order and second order adsorption models, diffusion based model was also employed to study adsorption kinetics of MB. Basically, heterogeneous adsorption process involves four types of resistances: Bulk, Film diffusion, Intra particle diffusion and Adsorption processes.
Among these, the intra-particle diffusion model involves pore (crack)/surface diffusion and is given by the following equation:

$Q_{t}=k_{i d} t^{0.5}+C$

where $k_{i d}$ is the intra particle diffusion rate constant and $C$ is the intercept which represents the boundary layer thickness. If the above Eq. (4) passes through the origin, the rate determining step is explained by intra particle diffusion. On the other hand, if the equation does not pass through the origin, film diffusion, in addition to intra particle diffusion, is involved which causes difference in the initial and final mass transfer rates. Figure $9 \mathrm{~d}$ shows the fitting plot of intra particle diffusion model. Two correlation coefficients were obtained as 0.9604 and 0.9915 . Since the plot passes through the origin, intra particle diffusion is the rate determining step for the adsorption process. Also, two different rate constants were obtained which can be explained as follows: 
Fig. 10 Mechanism of photocatalytic dye degradation by PANI

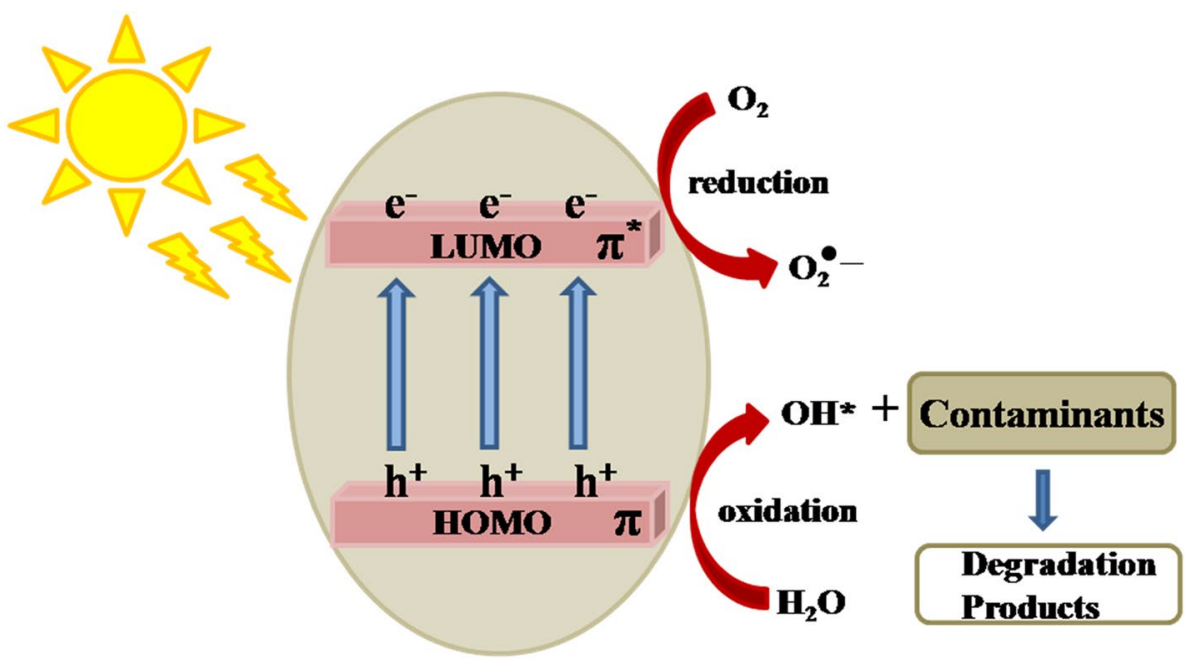

(1) Steep slope represents fast adsorption process implying electrostatic interaction between the dye molecules and the nanoparticles.

(2) Gradual slope signifies the slow process of diffusion of dye molecules into PANI.

\section{Mechanism}

The process of photo excitation, charge separation and electron-hole generation, is shown in Fig. 10. The energy of the polymer system is increased due to positive charges localized on neighboring nitrogen atoms which result in redistribution of electron density. In case of a polymer chain, the delocalized cation radicals provide electron conductivity. For PANI, the electron conductivity increases with the degree of protonation, and this is characteristic of polyaniline [32]. The lowest occupied molecular orbital (LOMO) and highest occupied molecular orbital (HOMO) of PANI is positioned at -1.9 and $0.8 \mathrm{eV}$ respectively [55]. When irradiated with visible light, conducting PANI absorbs photons and causes $\pi-\pi^{*}$ transition wherein the excited state electrons of $\mathrm{HOMO}$ and LUMO orbital undergo separation and are then transferred from the $\pi$ to the $\pi^{*}$ orbital $[55,56]$. The oxidative species that are formed on the catalyst surface, degrade the dye to form intermediates and final products like $\mathrm{CO}_{2}$, $\mathrm{SO}_{4}{ }^{2-}, \mathrm{NO}_{3}{ }^{-}, \mathrm{NH}_{4}{ }^{+}[55]$. Thus, the rapid charge generation and slow charge recombination leads to enhanced photocatalytic activity.

\section{Conclusion}

Herein, we outline the synthesis of Polyaniline through polymerization of aniline, for exploring its photocatalytic efficiency. The sample was prepared successfully using oxidative polymerization and was characterized using SEM,
TEM, FTIR, UV-Vis Spectroscopy and XPS which confirmed the morphological, optical and chemical bonding characteristics. PANI sample functioned effectively as a photocatalyst for both dyes, MB and MO, with high activity and stability. Kinetic analysis indicated that the reaction followed pseudo first order kinetics $\left(k_{1}=0.0505\right)$. The $\pi-\pi^{*}$ transition occurring in PANI is responsible for the generation of electron-hole pairs which enhance the degradation of the particles thus confirming efficient photocatalytic ability of PANI.

Acknowledgements Funding was provided by Science and Engineering Research Board (Grant No. ECR/2017/001222).

Author contributions MK: deduced and designed the experiment; NC, SS, AK: synthesized the material; SS, NC, AK: performed photocatalytic experiments, analyzed the data; SS: prepared the draft; MK, NC, SS: proofread the final draft; All authors approved the final manuscript.

\section{Compliance with ethical standards}

Conflict of interest The authors declare no competing financial interests.

\section{References}

1. Cao S, Low J, Yu J, Jaroniec M (2015) Polymeric photocatalysts based on graphitic carbon nitride. Adv Mater 27:2150-2176

2. Yu J, Li Q, Liu S, Jaroniec M (2013) Ionic-liquid-assisted synthesis of uniform fluorinated $\mathrm{B} / \mathrm{C}$-codoped $\mathrm{TiO}_{2}$ nanocrystals and their enhanced visible-light photocatalytic activity. Chem $A$ Eur J 19:2433-2441

3. Yu J, Low J, Xiao W, Zhou P, Jaroniec M (2014) Enhanced photocatalytic $\mathrm{CO}_{2}$-reduction activity of anatase $\mathrm{TiO}_{2}$ by coexposed 001 and 101 facets. J Am Chem Soc 136:8839-8842

4. Jang ES, Won JH, Hwang SJ, Choy JH (2006) Fine tuning of the face orientation of $\mathrm{ZnO}$ crystals to optimize their photocatalytic activity. Adv Mater 18:3309-3312 
5. Wang $X$, Liao $M$, Zhong $Y$, Zheng JY, Tian W, Zhai T, Zhi C, Ma Y, Yao J, Bando Y (2012) ZnO hollow spheres with double-yolk egg structure for high-performance photocatalysts and photodetectors. Adv Mater 24:3421-3425

6. Hu Y, Gao X, Yu L, Wang Y, Ning J, Xu S, Lou XWD (2013) Carbon-coated CdS petalous nanostructures with enhanced photostability and photocatalytic activity. Angew Chem 125:5746-5749

7. Xiang Q, Cheng B, Yu J (2013) Hierarchical porous CdS nanosheet-assembled flowers with enhanced visible-light photocatalytic $\mathrm{H}_{2}$-production performance. Appl Catal B 138:299-303

8. Hoffmann MR, Martin ST, Choi W, Bahnemann DW (1995) Environmental applications of semiconductor photocatalysis. Chem Rev 95:69-96

9. Muktha B, Madras G, Guru Row T, Scherf U, Patil S (2007) Conjugated polymers for photocatalysis. J Phys Chem B 111:7994-7998

10. Khojasteh H, Salavati-Niasari M, Mortazavi-Derazkola S (2016) Synthesis, characterization and photocatalytic properties of nickel-doped $\mathrm{TiO}_{2}$ and nickel titanate nanoparticles. J Mater Sci Mater Electron 27:3599-3607

11. Mortazavi-Derazkola S, Salavati-Niasari M, Mazhari M-P, Khojasteh H, Hamadanian M, Bagheri S (2017) Magnetically separable $\mathrm{Fe}_{3} \mathrm{O}_{4} @ \mathrm{SiO}_{2} @ \mathrm{TiO}_{2}$ nanostructures supported by neodymium(III): fabrication and enhanced photocatalytic activity for degradation of organic pollution. J Mater Sci Mater Electron 28:14271-14281

12. Zinatloo-Ajabshir S, Mortazavi-Derazkola S, Salavati-Niasari M (2017) Schiff-base hydrothermal synthesis and characterization of $\mathrm{Nd}_{2} \mathrm{O}_{3}$ nanostructures for effective photocatalytic degradation of eriochrome black T dye as water contaminant. J Mater Sci Mater Electron 28:17849-17859

13. Bhuyan T, Mishra K, Khanuja M, Prasad R, Varma A (2015) Biosynthesis of zinc oxide nanoparticles from Azadirachta indica for antibacterial and photocatalytic applications. Mater Sci Semicond Process 32:55-61

14. Sharma R, Khanuja M, Islam S, Singhal U, Varma A (2017) Aspectratio-dependent photoinduced antimicrobial and photocatalytic organic pollutant degradation efficiency of $\mathrm{ZnO}$ nanorods. Res Chem Intermed 43:5345-5364

15. Ebrahimzadeh MA, Naghizadeh A, Amiri O, Shirzadi-Ahodashti M, Mortazavi-Derazkola S (2020) Green and facile synthesis of Ag nanoparticles using Crataegus pentagyna fruit extract (CPAgNPs) for organic pollution dyes degradation and antibacterial application. Bioorg Chem 94:103425

16. Ebrahimzadeh MA, Mortazavi-Derazkola S, Zazouli MA (2019) Eco-friendly green synthesis and characterization of novel Fe 3 O 4/SiO 2/Cu 2 O-Ag nanocomposites using Crataegus pentagyna fruit extract for photocatalytic degradation of organic contaminants. J Mater Sci Mater Electron 30:10994-11004

17. Singh $S$, Pendurthi $R$, Khanuja $M$, Islam $S$, Rajput $S$, Shivaprasad $S$ (2017) Copper-doped modified $\mathrm{ZnO}$ nanorods to tailor its light assisted charge transfer reactions exploited for photo-electrochemical and photo-catalytic application in environmental remediation. Appl Phys A 123:184

18. Bhuyan T, Khanuja M, Sharma R, Patel S, Reddy M, Anand S, Varma A (2015) A comparative study of pure and copper (Cu)doped $\mathrm{ZnO}$ nanorods for antibacterial and photocatalytic applications with their mechanism of action. J Nanopart Res 17:288

19. Sharma R, Singh S, Verma A, Khanuja M (2016) Visible light induced bactericidal and photocatalytic activity of hydrothermally synthesized $\mathrm{BiVO}_{4}$ nano-octahedrals. J Photochem Photobiol B 162:266-272

20. Ranjeh M, Beshkar F, Amiri O, Salavati-Niasari M, Moayedi $H$ (2020) Pechini sol-gel synthesis of $\mathrm{Cu}_{2} \mathrm{O} / \mathrm{Li}_{3} \mathrm{BO}_{3}$ and $\mathrm{CuO} / \mathrm{Li}_{3} \mathrm{BO}_{3}$ nanocomposites for visible light-driven photocatalytic degradation of dye pollutant. J Alloys Compd 815:152451

21. Ranjeh M, Beshkar F, Salavati-Niasari M (2019) Sol-gel synthesis of novel Li-based boron oxides nanocomposite for photodegradation of azo-dye pollutant under UV light irradiation. Compos B Eng 172:33-40

22. Najafian H, Manteghi F, Beshkar F, Salavati-Niasari M (2018) Efficient degradation of azo dye pollutants on $\mathrm{ZnBi} 38058$ nanostructures under visible-light irradiation. Sep Purif Technol 195:30-36

23. Najafian $H$, Manteghi F, Beshkar F, Salavati-Niasari M (2019) Fabrication of nanocomposite photocatalyst $\mathrm{CuBi}_{2} \mathrm{O}_{4} / \mathrm{Bi}_{3} \mathrm{ClO}_{4}$ for removal of acid brown 14 as water pollutant under visible light irradiation. J Hazard Mater 361:210-220

24. Najafian H, Manteghi F, Beshkar F, Salavati-Niasari M (2019) Enhanced photocatalytic activity of a novel $\mathrm{NiO} / \mathrm{Bi}_{2} \mathrm{O}_{3} / \mathrm{Bi}_{3} \mathrm{ClO}_{4}$ nanocomposite for the degradation of azo dye pollutants under visible light irradiation. Sep Purif Technol 209:6-17

25. Ghosh S, Kouame NA, Remita S, Ramos L, Goubard F, Aubert P-H, Dazzi A, Deniset-Besseau A, Remita H (2015) Visible-light active conducting polymer nanostructures with superior photocatalytic activity. Sci Rep 5:srep18002

26. Ma D, Aguiar M, Freire JA, Hümmelgen IA (2000) Organic reversible switching devices for memory applications. Adv Mater 12:1063-1066

27. Sirringhaus $H$, Tessler N, Friend RH (1998) Integrated optoelectronic devices based on conjugated polymers. Science 280:1741-1744

28. Vyas VS, Lotsch BV (2015) Materials chemistry: organic polymers form fuel from water. Nature 521:41-42

29. Kumar S, Wani MY, Arranja CT, e Silva JdA, Avula B, Sobral AJ (2015) Porphyrins as nanoreactors in the carbon dioxide capture and conversion: a review. J Mater Chem A 3:19615-19637

30. Vyas VS, Lau VW, Lotsch BV (2016) Soft photocatalysis: organic polymers for solar fuel production. Chem Mater 28:5191-5204

31. Calik M, Auras F, Salonen LM, Bader K, Grill I, Handloser M, Medina DD, Dogru M, Löbermann F, Trauner D (2014) Extraction of photogenerated electrons and holes from a covalent organic framework integrated heterojunction. J Am Chem Soc 136:17802-17807

32. Boeva ZA, Sergeyev V (2014) Polyaniline: synthesis, properties, and application. Polym Sci Ser C 56:144-153

33. Ghanbari K, Mousavi M, Shamsipur M (2006) Preparation of polyaniline nanofibers and their use as a cathode of aqueous rechargeable batteries. Electrochim Acta 52:1514-1522

34. Jussila S, Puustinen M, Hassinen T, Olkkonen J, Sandberg HG, Solehmainen K (2012) Self-aligned patterning method of poly(aniline) for organic field-effect transistor gate electrode. Org Electron 13:1308-1314

35. Wang W, Lu X, Li Z, Lei J, Liu X, Wang Z, Zhang H, Wang C (2011) One-dimensional polyelectrolyte/polymeric semiconductor core/shell structure: sulfonated poly(arylene ether ketone)/ polyaniline nanofibers for organic field-effect transistors. Adv Mater 23:5109-5112

36. Choi MR, Han TH, Lim KG, Woo SH, Huh DH, Lee TW (2011) Soluble self-doped conducting polymer compositions with tunable work function as hole injection/extraction layers in organic optoelectronics. Angew Chem 123:6398-6401

37. Zhang Y, Chen P, Wen F, Huang C, Wang H (2016) Construction of polyaniline/molybdenum sulfide nanocomposite: characterization and its electrocatalytic performance on nitrite. lonics 22:1095-1102

38. Tian $Z$, Yu H, Wang L, Saleem $M$, Ren F, Ren $P, C$ hen $Y$, Sun R, Sun $Y$, Huang $L$ (2014) Recent progress in the preparation of polyaniline nanostructures and their applications in anticorrosive coatings. RSC Adv 4:28195-28208 
39. Ayad M, Zaghlol S (2012) Nanostructured crosslinked polyaniline with high surface area: synthesis, characterization and adsorption for organic dye. Chem Eng J 204:79-86

40. Xu F, Zheng G, Wu D, Liang Y, Li Z, Fu R (2010) Improving electrochemical performance of polyaniline by introducing carbon aerogel as filler. Phys Chem Chem Phys 12:3270-3275

41. Rangel-Vazquez N-A, Sánchez-López C, Felix FR (2014) Spectroscopy analyses of polyurethane/polyaniline IPN using computational simulation (Amber, $\mathrm{MM}+$ and $\mathrm{PM} 3$ method). Polímeros 24:453-463

42. Pruneanu S, Veress E, Marian I, Oniciu L (1999) Characterization of polyaniline by cyclic voltammetry and UV-Vis absorption spectroscopy. J Mater Sci 34:2733-2739

43. Gruger A, Novak A, Regis A, Colomban P (1994) Infrared and Raman study of polyaniline part II: influence of ortho substituents on hydrogen bonding and UV/Vis-near-IR electron charge transfer. J Mol Struct 328:153-167

44. Jain S, Chakane S, Samui A, Krishnamurthy V, Bhoraskar S (2003) Humidity sensing with weak acid-doped polyaniline and its composites. Sens Actuators B Chem 96:124-129

45. Golczak S, Kanciurzewska A, Fahlman M, Langer K, Langer JJ (2008) Comparative XPS surface study of polyaniline thin films. Solid State Ion 179:2234-2239

46. Pandiselvi K, Fang H, Huang X, Wang J, Xu X, Li T (2016) Constructing a novel carbon nitride/polyaniline/ZnO ternary heterostructure with enhanced photocatalytic performance using exfoliated carbon nitride nanosheets as supports. J Hazard Mater 314:67-77

47. Sha C, Lu B, Mao H, Cheng J, Pan X, Lu J, Ye Z (2016) 3D ternary nanocomposites of molybdenum disulfide/polyaniline/reduced graphene oxide aerogel for high performance supercapacitors. Carbon 99:26-34

48. Binkauskienè $E$, Jasulaitienè V, Lugauskas A (2009) Effect of Aspergillus niger Tiegh. L-10 on the physical and chemical properties of a polyaniline coating in the growth substrate. Synth Met 159:1365-1368
49. Subramanian N, Viswanathan B (2015) Nitrogen-and oxygencontaining activated carbons from sucrose for electrochemical supercapacitor applications. RSC Adv 5:63000-63011

50. Saha S, Chaudhary N, Mittal H, Gupta G, Khanuja M (2019) Inorganic-organic nanohybrid of $\mathrm{MoS}_{2}$-PANI for advanced photocatalytic application. Int Nano Lett 9:127-139

51. Singh SA, Madras G (2013) Photocatalytic degradation with combustion synthesized $\mathrm{WO}_{3}$ and $\mathrm{WO}_{3} \mathrm{TiO}_{2}$ mixed oxides under UV and visible light. Sep Purif Technol 105:79-89

52. Han S, Liu K, Hu L, Teng F, Yu P, Zhu Y (2017) Superior adsorption and regenerable dye adsorbent based on flower-like molybdenum disulfide nanostructure. Sci Rep 7:43599

53. Massey AT, Gusain R, Kumari S, Khatri OP (2016) Hierarchical microspheres of $\mathrm{MoS}_{2}$ nanosheets: efficient and regenerative adsorbent for removal of water-soluble dyes. Ind Eng Chem Res 55:7124-7131

54. Hwang K-J, Shim W-G, Kim Y, Kim G, Choi C, Kang SO, Cho DW (2015) Dye adsorption mechanisms in $\mathrm{TiO}_{2}$ films, and their effects on the photodynamic and photovoltaic properties in dye-sensitized solar cells. Phys Chem Chem Phys 17:21974-21981

55. Wang Q, Hui J, Li J, Cai Y, Yin S, Wang F, Su B (2013) Photodegradation of methyl orange with PANI-modified BiOCl photocatalyst under visible light irradiation. Appl Surf Sci 283:577-583

56. Deng Y, Tang L, Zeng G, Dong H, Yan M, Wang J, Hu W, Wang J, Zhou Y, Tang J (2016) Enhanced visible light photocatalytic performance of polyaniline modified mesoporous single crystal $\mathrm{TiO}_{2}$ microsphere. Appl Surf Sci 387:882-893

Publisher's Note Springer Nature remains neutral with regard to jurisdictional claims in published maps and institutional affiliations. 